\title{
The Effectiveness of Enrichment Activities Program Based on Educational Techniques on the Quality of Mathematics Outcomes for Third-Grade Primary Students in Jordan
}

\author{
Haya Abed Ahmad Homedan, Nashaat Baioumy, Tasnim Binti Mohd Annuar
}

To Link this Article: http://dx.doi.org/10.6007/IJARBSS/v11-i5/9854

DOI:10.6007/IJARBSS/v11-i5/9854

Received: 05 March 2021, Revised: 08 April 2021, Accepted: 25 April 2021

Published Online: 08 May 2021

In-Text Citation: (Homedan et al., 2021)

To Cite this Article: Homedan, H. A. A., Baioumy, N., \& Annuar, T. B. M. (2021). The Effectiveness of Enrichment Activities Program Based on Educational Techniques on the Quality of Mathematics Outcomes for ThirdGrade Primary Students in Jordan. International Journal of Academic Research in Business and Social Sciences, 11(5), 63-76.

\section{Copyright: @ 2021 The Author(s)}

Published by Human Resource Management Academic Research Society (www.hrmars.com)

This article is published under the Creative Commons Attribution (CC BY 4.0) license. Anyone may reproduce, distribute, translate and create derivative works of this article (for both commercial and non-commercial purposes), subject to full attribution to the original publication and authors. The full terms of this license may be seen at: http://creativecommons.org/licences/by/4.0/legalcode

Vol. 11, No. 5, 2021, Pg. 63 - 76 


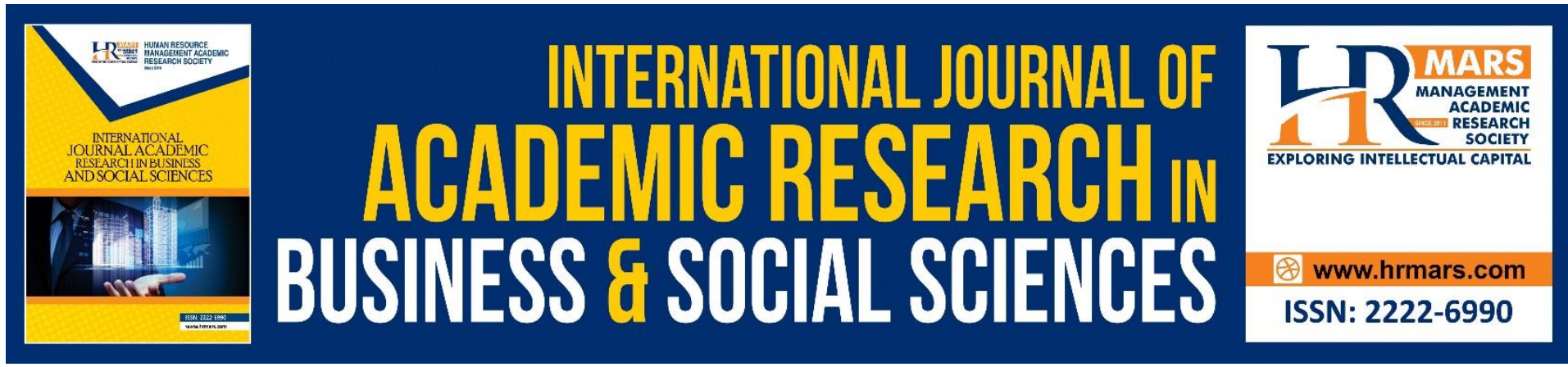

\title{
The Effectiveness of Enrichment Activities Program Based on Educational Techniques on the Quality of Mathematics Outcomes for Third-Grade Primary Students in Jordan
}

\section{Haya Abed Ahmad Homedan, Nashaat Baioumy, Tasnim Binti Mohd Annuar}

Faculty of Islamic Contemporary Studies, University Sultan Zainal Abidin, Gong Badak

Campus, 21300 Kuala Nerus, Terengganu, MALAYSIA

Email: nashaatbaioumy@unisza.edu.my

\begin{abstract}
This study aimed to identify the effectiveness of enrichment activities program based on educational techniques on the quality of mathematics output for third-grade students in Jordan. To achieve the goal of the study, the researcher followed the descriptive and quasiexperimental approach to obtain the results. The study community consisted of primary thirdgrade students in public schools affiliated to the Directorate of Educational Training in the Governorate of Jerash in (2019/2020) first semester. The study sample consisted of (60) male and female students from the third basic grade, chosen by the random cluster method. A program for enrichment activities based on educational techniques was built, appropriate statistical analyzes were conducted. Through arithmetic means and standard deviations, and the (t-test), quantitative results were extracted. The most important results of the study were: The presence of a statistically significant difference at the level of statistical significance (0.05) between the outputs of experimental and control groups in the test post application with the unit of adding numbers within 9999 and introducing it for third grade students' mathematics in Jordan, for the benefit of the experimental group.
\end{abstract}

Keywords: Effectiveness, Enrichment Activities Program, Educational Techniques, Educational Outcomes, Third Grade.

\section{Introduction}

The technological and informatics revolution has brought about a major change in teaching and learning strategies. The use of modern technologies in the educational process has helped to shift from traditional teaching to activity-based teaching. The use of computers, the Internet and e-mail have also helped develop distance learning methods, and develop active teaching methods. In addition, it facilitates communication between students and their teachers, and the use of technologies in education has contributed to achieving the quality of educational process. 
There is no doubt that progress in technology is nothing but the production of scientific progress. Therefore, the level of educational progress and the efforts and funds expended to it contribute directly to reaching new innovations in the scientific field, and the multiple technical applications that follow. On the other hand, progress in the field of technology can have its impact on the development of education, through its use in developing educational content, supporting school administrative procedures, opening new horizons in teaching and learning, through technical education, and developing teaching methods and approaches of teacher preparation and development (Ar-Rasheed, 2017).

Educational technology is an important component that cannot be ignored; and that is due to its great effects in the educational process. These means and tools were and will remain the primary assistant for the teacher in the classroom, as they initially included simple educational aids: books, blackboards, pictures, projectors and cinematography. Then the classroom developed with the introduction of educational technologies represented in the computer, the smart board, and others. It is through the merging of visual technologies with audio technologies that the various means were formed which led to the increasing use of technology in education (Yahn, 2017).

\section{Problem of the Study}

In the current era, educational technology has become a basic requirement of this era. What confirms this idea is what was indicated by (Yahn, 2017) that technology, with the educational technologies it contains, encouraged those in charge of educational systems to make use of these technologies in the educational process. It provides various opportunities for learning, as it makes learning more learner-focused and transfers the role of the learner from receiving information, to researcher and participant in the education process.

The problem of studying lies in the researcher's experience, as the researcher works in public schools, and is aware of the educational conditions and records of students 'grades in schools. It is still characterized by traditionalism, and their lack of employment of educational means that contribute to facilitating mathematics concepts, develop creativity and thinking among students, enhance their motivation, and deepen their acquisition of concepts, mental skills and positive attitudes.

In view of the lack of studies and research in this field, hence the importance of this research is an attempt to uncover the effectiveness of enrichment activities program based on the use of educational techniques in the quality of mathematics output for third-grade basic students in Jordan.

\section{Study Questions}

1. What are the foundations for preparing a program for enrichment activities based on educational techniques in light of the quality standards of the outputs of unit collection of numbers within 9999 and introducing them for third-grade basic students' mathematics in Jordan?

2. What is the effectiveness of the proposed program for enrichment activities based on educational techniques in the quality of the outputs of unit collection of numbers within 9999 and introducing them for third-grade basic students' mathematics in Jordan?

\section{Objectives of the Study}

1. Disclosure of the foundations for preparing enrichment activities program based on educational techniques in light of the quality standards of the outputs of unit collection 
numbers within 9999 and its introduction to third-grade basic students mathematics in Jordan.

2. Exposing the effectiveness of enrichment activities program based on educational techniques in the quality of the outputs of unit collection of numbers within 9999 and its introduction to third-grade basic students mathematics in Jordan.

\section{Importance of the Study}

It is hoped that the following bodies will benefit from the results of the study:

1. Mathematics curriculum planners: By making use of its topic, by developing programs based on the use of educational techniques, to achieve the quality of educational outcomes of mathematics for the lower basic grades.

2. Those responsible for developing the educational process: to develop enrichment activities programs in the content of mathematics for the lower basic grades based on the use of educational techniques.

3. Mathematics teachers: by employing the program based on the use of educational techniques to raise the level of students' academic achievement in mathematics to achieve the quality of educational process outcomes.

4. Researchers: It is hoped that they will benefit from the study as a reference to help them build their subsequent research with the information it will provide, the theoretical literature and previous studies it provides, and a program based on the use of educational techniques.

\section{Limitations of the Study}

This research is objectively limited to the following:

1. Objective limits: The current study deals with knowing the effectiveness of the proposed program in the quality of outputs of unit collection of numbers within 9999 and introducing them for third-grade basic students' mathematics in Jordan.

2. Spatial boundaries: The study is limited to two basic stage schools in Jerash Governorate / Jordan.

3. Time limits: The field study was applied in the first semester of the year $2019 / 2020$.

4. Human boundaries: limited to third-grade students, male / female.

\section{Terminology of the Study}

- Effectiveness: is the extent of the impact that the enrichment activities can have as an independent variable in one of the dependent variables (Badr et al., 2016).

- The researcher defines it procedurally: as the positive effect of using enrichment activities program based on teaching techniques in third grade mathematics, in order to raise the level of students' academic achievement.

- The Program: It is a training activity aimed at bringing about current or future behavioral and mental changes in the individual (Abdul-Ghani, 2018).

- Procedurally: it is a system developed according to specific, studied scientific foundations to raise the level of academic achievement of third-grade students in basic mathematics to achieve the quality of the educational process outcomes.

- The Activities Enrichment Program: It is a set of additional educational experiences that are profound and varied and are represented by scientific modifications or additions, projects, curricula and special programs that meet students' needs, suit their mental abilities, and are related to scientific content, or mental and skill capabilities (Jarwan, 2004)). 
- As for procedural aspect, the researcher defines it as: mathematics related activities based on educational techniques that have been added to the subject with the aim of raising the level of academic achievement of third-grade students.

- Teaching technologies: They are all devices, equipment and tools that are used by teachers and students in the educational situation individually or collectively, in order to achieve the principles of individual learning and active learning, with the aim of developing the educational learning process (Al-Balawi, 2014).

- Procedurally, the researcher defines it as: educational media, and all the educational tools and methods associated with it, that teachers use with third grade students in basic mathematics in order to raise the level of students' academic achievement and work to achieve the quality of educational process outputs such as: the smart board, the tablet computer educational phone and educational games.

- Education outcomes: It is the exact term that describes what the student is expected to acquire in terms of knowledge, abilities and skills during the school year (Al-Tasan, 2015).

- Third grade: one of the first basic stage classes, which starts from the first grade of the third grade, and the ages of students range from (6-8) years.

\section{The Theoretical Framework of the Study}

Education technologies are considered the latest findings of educational scientists in this era, where attention has shifted from educational means as devices and materials only to concern for the essence of educational process in terms of materials and devices and the human element involved in the educational process as they are all basic and complementary to each other, and what it must achieve in terms of various behavioral and cognitive goals. There remains an integrated educational system, and the presence of a teacher qualified to use it. This system is related to both the educational psychology foundations and also to educational resources with a focus on individual differences between students, their tendencies, attitudes, and the pupil's interests and motivations towards learning. Education techniques are an organized, purposeful and correct application of educational systems, and the development of the learning and teaching process with the aim of providing educational experiences appropriate to the needs of learners, to help the learner learn (Al-Helah, 2001).

\section{Characteristics of Modern Education Technologies}

Modern technologies for education have a number of common characteristics, which are various characteristics derived from modern learning theories, namely:

1. Interactivity: Modern education technologies provide a communication environment that is at least two-way to the user, allowing dialogue and interaction between the two ends of educational process for the learner and the program, and interaction between the user and the technology takes place, so the learner proceeds in the educational content and receives feedback.

2. Individualism: related to the individuality of the learner in the educational method and overcoming the problem of individual differences between the learners and the access of all learners to mastery level according to the abilities, aptitudes, experiences, level of intelligence and the learner's ability to think, remember and retrieve information.

3. Total quality: related to providing all the requirements of the physical education technologies represented by hardware, tools and software, and the human element that is able to deal with the technologies so that it is able to achieve the desired goals with the least time, effort and cost (Adam, 2012). 


\section{Education and Mathematics Techniques}

Due to the importance of technology in learning mathematics, the National Council of Mathematics Teachers in America (NCTM) has adopted the "principle of technology" as one of the principles on which school mathematics is based. This principle states the importance of using modern technology in learning mathematics represented by computers, educational software and calculator machines because of its great impact on improving and facilitating pupils' learning, organizing and analyzing data, being able to do arithmetic operations quickly and with complete accuracy, and helping to search in all branches of mathematics (2000NCTM).

\section{Principles of Employing Modern Technologies in Teaching and Learning Mathematics}

Al-Suruur (2014) emphasized the principles of employing modern technology in the field of learning mathematics, including:

1. More than one educational method can be used to achieve the educational goal.

2. The quality of educational software designed for individual education and self-learning depends on the efficiency of the work team that prepared it, and the opportunity for each student to interact with the educational content of the subject, and the use of mathematical thinking skills.

3. Benefiting from the designed educational software, so that the teacher has roles accompanying the learning process, such as managing discussion and class dialogue, stops during the lesson to achieve mathematical interaction and communication between students. 4. The lesson is not only in the efficiency of employing modern technologies, but rather in the clarity of educational goals that were previously planned to take advantage of technologies.

\section{The Importance of using Educational Techniques in Teaching Mathematics}

Educational research and studies have emphasized the use of educational techniques in teaching mathematics in particular, as it achieves many advantages that have been identified by (Al-Hadi, 2005) as follows:

1. Achieving the joy of learning, as technology stimulates and attracts students 'attention towards learning.

2. Achieving individual's principle or self-learning for the variation in abilities among pupils.

3. Cooperative learning through: dialogue and communication between educational software and the learner.

4. Reducing learning time compared to regular traditional learning.

5. The availability of visual information and data through static, moving images and graphics, and the availability of the movement component.

6. Availability of the simulation component and the modeling ability.

\section{Literature Review}

Abu Nahleh (2018) conducted a study aimed at identifying the effect of using the interactive board on creative thinking in mathematics among eighth grade female students in Jordan. The researcher used the quasi-experimental approach, and the study sample was chosen by the intentional method, and it consisted of (40) basic eighth grade female students. The researcher used the creative thinking test in the pre and post application after confirming its validity and reliability, and used the t-test and the accompanying multiple analyses of variance (ANCOVA) to answer the study questions. The results of the study showed: There are statistically significant differences between the average performance of the two study 
groups on the creative thinking test (fluency, originality, and flexibility) in favor of the experimental group that studied using the interactive whiteboard.

Hajbi (2017) conducted a study aimed at investigating the effect of teaching a mathematically computerized unit using a tablet computer on the achievement of tenth grade students in basic mathematics and improving motivation towards it. The researcher followed the semi-experimental approach, and the study sample was intentionally chosen. In order to achieve the objectives of the study, the researcher computerized the unit of statistics and probabilities from the tenth grade mathematics book, and used the achievement test and a measure of motivation towards learning mathematics. The results of the study showed that there are statistically significant differences in the achievement of the tenth primary grade female students, and it increases the motivation towards learning mathematics for the benefit of the experimental group that studied the mathematically computerized unit using the tablet computer.

Al-Khatib (2015) conducted a study aimed at investigating the effect of the effectiveness of using the electronic whiteboard on the achievement of sixth-graders in basic mathematics and their attitudes towards it. The study sample was intentionally chosen from the sixth grade students. The researcher used the experimental approach to achieve the objectives of the study in this study. The results of this study showed that: There were statistically significant differences between the mean scores of the two groups' students in favor of the experimental group. The results of the study revealed positive trends among students towards using the electronic board in learning. The researcher recommended the use of electronic blackboard in teaching mathematics, due to its clear impact on achievement, and conducting a number of studies on the effectiveness of electronic board in students' achievement in mathematics and their attitudes towards the electronic board.

Tunaboyin and Demir (2017) conducted a study that aimed at investigating the effect of using the interactive whiteboard on the achievement of seventh-grade students in mathematics. The study was conducted in Turkey, the study sample consisted of (58) students, and they were divided into two groups, experimental and control. The results of the study showed that the use of an interactive board in the process of teaching mathematics had positive effects on academic achievement.

Shman-East (2015) conducted a study that aimed at identifying the effectiveness of electronic cognitive training in enhancing memory and achievement in mathematics among primary school students with low mathematics achievement. The researcher used the semiexperimental approach, and the study sample consisted of (30) male and female students from the fifth grade students in Florida, America. They were divided into two groups: the experimental group, which numbered (15) male and female students, and the control group, which numbered (15) male and female students. The results showed: The experimental group that studied electronic cognitive training was superior to the control group that studied through the usual method. And the experimental group students achieved better than the control group.

\section{Study Approach}

The current study followed the descriptive and quasi-experimental approach in building the program and in building the research experience to know the effectiveness of the proposed program for enrichment activities based on educational techniques in the quality of the outputs of unit number collection within 9999 and its introduction to third-grade students' mathematics in Jordan 


\section{Study Population}

The research community consists of all third-grade students in government public schools affiliated to the Directorate of Education in Jerash Governorate in the first semester of 2019/2020 academic year and their number is $(13,500)$ male and female students, according to the Ministry of Education statistics for the year 2019/2020.

\section{The Sample of the Study}

Exploratory sample: where the researcher chose an exploratory sample to test the study tools, which consisted of (25) male and female students.

Actual sample: The study sample consisted of (60) male and female students chosen by the random cluster method. Table (1) shows the distribution of the study sample individuals. Table (1) shows the distribution of the sample members for the third grade students

\begin{tabular}{crrr}
\hline $\begin{array}{r}\text { The sex of the } \\
\text { pupils }\end{array}$ & Number of pupils & School & the group \\
Male and female & 30 & $\begin{array}{r}\text { The future of Mixed } \\
\text { Comprehensive } \\
\text { Secondary } \\
\text { mixed }\end{array}$ & Experimental group \\
Male and female & 30 & Kefir $\begin{array}{r}\text { Control group } \\
\text { comprehensive } \\
\text { secondary }\end{array}$ & \\
& & & \\
\hline
\end{tabular}

60 Male and female students Total

Study tool: To achieve the objectives of the study, and to answer the questions, the theoretical literature and previous studies that dealt with educational technologies and their impact on mathematics achievement at the basic education stage were referred to, and enrichment activities program based on educational technologies was built.

\section{Validating the Tool Content}

To verify the validity of the study tool, the researcher presented the program to a group of referees specialized in teaching curricula and methods, specialists in computer and programming, educational techniques, and teachers of the third grade. Their number reached (13) arbitrators in order to express their observations on the extent of its suitability to achieve its goals in light of educational material content, the suitability of the topics for the third grade basic students, the relevance of the enrichment activities to achieve its objectives, the extent of the validity of linguistic formulation, and the researcher's commitment to the standards of educational software production. In light of the remarks of the referees, the researcher modified the program and it was taken out in its final form.

\section{Statistical Processors}

- T-test for independent samples.

- The arithmetic means and standard deviations of the responses of research sample individuals.

\section{Displaying the Results and Discussion of the Study}

The results of the first question: What are the foundations for preparing enrichment activities program based on educational techniques in light of the quality standards of the 
outputs of unit of collecting numbers within 9999 and introducing them to third-grade basic students' mathematics in Jordan?

The preparation of enrichment activities program based on one of the educational techniques does not come by accident or in an unplanned way; rather, it is based on agreed foundations and rules in preparing enrichment activities program based on appropriate educational techniques for each educational situation.

\section{Program Building Foundations}

The program was based on a number of foundations, namely:

\section{The Intellectual (philosophical) basis}

The mathematics curriculum in the Hashemite Kingdom of Jordan is considered a basic education curriculum for all academic levels, as mathematics is distinguished from other sciences starting from the number of classes allocated to it in Jordanian schools from other subjects. Since mathematics is distinguished by its imperative for other sciences, it is not possible for us to practice chemistry, physics, and even geology, and sociology without using mathematics, as mathematics provides a type of basic rules that differs from other subjects, as it is a cumulative science that always moves forward because its present and future are mainly based on the beginning. It is an abstract science based on numerical and geometric relationships where It is characterized by its accuracy, arrangement and gradation to present ideas, which helps in reaching the interpretations. Thus, mathematics is associated with various meanings, some considered it an arithmetic skill and some considered it a tool used in various fields of daily life, while scientists and specialists defined it as a method and experimental thinking method, through which methods of thinking are developed and thoroughly used with utmost precision and innovation. Therefore, mathematics is a universal language. They use unified symbols in order to communicate ideas between individuals, and they also contribute to intellectual communication between all members of society.

Hence, this program is based on the foundations on which the philosophy that defines the mathematics curriculum in schools at the Jordanian Ministry of Education is based, which is that the mathematics curriculum is essential for individual because it is part of society and thus he must interact with people in society. Therefore, individual must know the surrounding evidence, whether in commercial dealings such as buying and selling, or for productive and consumer dealings, all of these transactions are in dire need of basic mathematical knowledge that enables individual to simply and easily deal with others because of the various benefits of that for society.

\section{Psychological basis}

The program is concerned with developing the skill of addition and subtraction in mathematics for third-grade basic students in Jordanian schools in Jerash governorate and taking into account the characteristics of Jordanian students in the primary stage. This is in the belief of the researcher that growth in mastering this skill in mathematics is affected by other aspects of development that affects them and their characteristics as they are at an early age, whose ages range from (6-8) years, and is considered a basic stage characterized by rapid growth, frequent movement and love of discovery, forming trends towards learning, crystallizing tendencies and acquiring skills.

The program takes into account the individual differences between students, works to achieve the student's goal and satisfies his desires, and takes into account the student's 
needs, preparations, preferences, abilities and skills in the various educational stages as the focus of the educational learning process, as it makes him take from diversity as the basis for the student's educational activity, his learning resources, strategies for his progress, and gradation. In displaying and presenting its contents, and from facilitating its clarity, an opportunity to develop mathematics achievement for the unit of adding numbers within 9999 and introducing them to the middle and weak, and enriching the needs of outstanding students, to enable them to apply addition and subtraction skills in their daily lives.

\section{Social basis}

The program stems from the fact that teaching the unit of adding numbers within 9999 and introducing it with mathematics in the Jordanian society is a responsibility of various social media, most notably: home, school, and society. Therefore, this program strives to develop students' addition and subtraction skill and develop their abilities to deal in mathematical fields through classroom and non-classroom activities through those social media, through assignments and exercises to master the skill of addition and subtraction and employ it in daily life.

\section{Pedagogical basis}

The program helps in organizing educational learning situations, and the progression in presenting and providing sports information and employing it through activities and multiple sports, and the appropriate selection of learning conditions at the level of integration between the elements of educational material. The researcher believes that the educational foundations are elements in an integrated framework, so it is not possible to imagine a goal without content, and there is no content without a method that would be presented to the students, nor is there any modification in educational process field without evaluation, and these elements are all linked to each other in an integrated manner, so that each element is affected by other elements, and these elements are: What do we know? Why do we know? How do we know? How do we judge the results?

Accordingly, the program contributes to achieving the objectives of educational process in order to assess the needs of the pupils and increase their level of achievement. The program adopts the principle of learning as an educational basis that gives students the appropriate opportunity to practice sports through various activities and sports that strengthen the process of understanding, comprehension and mastery. Therefore, the program goes beyond the school environment as the learning environment is not the classroom alone, and the source of learning is not the textbook alone, but extends outside the classrooms and classrooms to outside the school, and to include multiple learning sources in which learning is done by modern technical methods and means.

The results of the second question: What are the effectiveness of the proposed program for enrichment activities based on educational techniques in the quality of the outputs of unit collection of numbers within 9999 and its introduction for third-grade basic students' mathematics in Jordan?

From this question, the following hypotheses were derived:

1. There is no statistically significant difference at the level of significance (05.0) between the outputs of experimental and control groups in the pre-application of the test with the unit of adding numbers within 9999 and introducing it for third-grade basic students' mathematics in Jordan. 
2. There is no statistically significant difference at the level of significance (05.0) between the outputs of experimental and control groups in the post application of the test in the unit of adding numbers within 9999 and introducing it for third-grade basic students' mathematics in Jordan.

To answer the first hypothesis, which reads: "there is no statistically significant difference at the level of significance (05.0) between the outputs of experimental and control groups in the pre-application of the test in the unit of adding numbers within 9999 and introducing it to the third-grade basic students' mathematics in Jordan"? The variables were adjusted and the parity of the two groups (experimental and control) was checked by conducting the pre-test as a step to achieve parity and to identify the outputs of the two groups in the pre-test. For third-grade basic students' mathematics in Jordan, the results were as follows:

Table no. (2) It shows the arithmetic mean, standard deviation, and ( $t$ ) value to indicate the differences between the mean outcomes of the experimental and control groups in the pretest.

\begin{tabular}{rrrrrrrr}
\hline comment & $\begin{array}{r}\text { Statistical } \\
\text { significance }\end{array}$ & $\begin{array}{r}\mathrm{T} \\
\text { value }\end{array}$ & $\begin{array}{r}\text { standard } \\
\text { deviation }\end{array}$ & SMA & $\begin{array}{r}\text { the } \\
\text { number }\end{array}$ & $\begin{array}{r}\text { Test } \\
\text { type }\end{array}$ & the group \\
\hline Not & .886 & 0.143 & 3.22 & 7.90 & 30 & \multirow{2}{*}{ Tribal } & Control \\
\cline { 4 - 7 } functioning & & & 2.05 & 8.00 & 30 & Experimental \\
\hline
\end{tabular}

It is evident from Table No. (2) test (T) for independent samples to find out the differences between the outputs of experimental and control groups in the pre-application of the test with the unit of adding numbers within 9999 and introducing it to the third basic class students' mathematics in Jordan at a significance level (0.05), as the results showed no statistical significance difference at the level of significance (0.05) between the outputs of experimental and control groups in the pre-application of the test in the unit of adding numbers within 9999 and introducing it to the third basic class students' mathematics in Jordan, where the value of $t$ was $(-0.143)$ and in statistical terms (0.886), where the arithmetic mean of the control group was (7.90) compared to the arithmetic mean of the experimental group (8.00) and it appears from the same table that the value of the two averages are close and weak, as indicated by the average achievement of the two groups in the pre-test.

Based on the results, the first null hypothesis was accepted, which states: "There is no statistically significant difference at the level of significance (05.0) between the outputs of experimental and control groups in the pre-application of the test in the unit of adding numbers within 9999 and introducing it to third-grade basic students' mathematics in Jordan".

To answer the second hypothesis, which reads: "there is no statistically significant difference at the level of significance (05.0) between the outputs of the experimental and control groups in the post application of the test in the unit of adding numbers within 9999 and introducing it to third-grade basic students' mathematics in Jordan"?

To answer this hypothesis, the researcher used the $(T)$ test for independent samples to find the differences between the outputs of experimental and control groups in the post application of the test in the unit of adding numbers within 9999 and introducing it to third grade students' mathematics in Jordan at a significance level of (0.05). The results are as follows. 
Table No. (3) It shows the arithmetic mean, standard deviation, and ( $t$ ) value to indicate the differences between the outputs of control and experimental groups in the post-test.

\begin{tabular}{r|r|r|r|r|r|r|r}
\hline comment & $\begin{array}{r}\text { Statistical } \\
\text { significance }\end{array}$ & $\begin{array}{r}\mathrm{T} \\
\text { value }\end{array}$ & $\begin{array}{r}\text { standard } \\
\text { deviation }\end{array}$ & $\mathrm{SMA}$ & $\begin{array}{r}\text { the } \\
\text { number }\end{array}$ & Test type & the group \\
\hline \multirow{2}{*}{ Function } & \multirow{2000}{*}{-8.61} & 3.22 & 7.90 & 30 & & Control \\
\cline { 4 - 6 } & & 2.01 & 13.87 & 30 & Dimensional & Experimental \\
\hline
\end{tabular}

Table (3) shows a (T) test for independent samples to find out the differences between the outputs of experimental and control groups in the post application of the test in the unit of adding numbers within 9999 and introducing it for the third basic grade students' mathematics in Jordan at the significance level (0.05), where the results showed a statistically significant difference at a level of significance (0.05) between the outputs of the experimental and control groups in the post application of the test in the unit of adding numbers within 9999 and introducing them to third basic grade students' mathematics in Jordan, where the value of $t$ was $(-8.61)$ and $(0.00)$ in statistical significance. These differences are attributed to the experimental group with an arithmetic mean (13.87) compared to the arithmetic mean of the control group (7.90), and this indicates the effectiveness of the program in the quality of mathematics outputs for the third basic grade among the experimental group students.

Based on the results, the second null hypothesis was rejected, which states: "There is no statistically significant difference at the level of significance (05.0) between the outputs of the experimental and control groups in the post application of the test in the unit of adding numbers within 9999 and introducing it to the third-grade basic students' mathematics in Jordan".

Acceptance of the alternative hypothesis included, "There is a statistically significant difference at the level of significance (0.05) between the outputs of the experimental and control groups in the post application of the test with the unit of addition of numbers within 9999 and its introduction of mathematics for third-grade basic students in Jordan."

The results indicated that there was no statistically significant difference at a significance level $(0.05)$ between the outputs of the experimental and control groups in the pre-application of the test in the unit of adding numbers within 9999 and introducing it to third-grade basic students' mathematics in Jordan. The value of the two averages appeared close, and the achievement averages of the students of the two groups revealed their poor performance in the pre-test. The researcher attributes this result to the fact that the two groups studied the educational unit in the usual way.

The results showed that there was a statistically significant difference at a level of significance (0.05) between the outputs of experimental and control groups in the post application of the test in the unit of adding numbers within 9999 and introducing it to thirdgrade basic students' mathematics in Jordan. This difference is attributed to the benefit of experimental group, and the difference appeared large, and the emergence of a large difference indicates the effectiveness of the program in the quality of mathematics output. The researcher can attribute this result to the superiority of the experimental group over the control group members to the fact that the members of the experimental group found that the proposed program for enrichment activities based on educational techniques in the number collection unit within 9999 and presented to the third-grade basic students in Jordan, is the ability of educational techniques to make the pupil active and effective. During his acquisition of experiences and skills in educational situations in which there is excitement, competition, reinforcement, and happiness, the employment of modern educational technologies in teaching mathematics has worked to employ more than one sense for the 
student in learning, such as the auditory and visual sense. The student's role is no longer passive, but his role has become positive, participatory and effective during learning, which breaks the barrier of stagnation and overcomes the abstraction characteristic of mathematics.

In addition, the use of enrichment activities in the teaching of mathematics achieves many positive effects on the desired learning outcomes, and these enrichment activities have proven their effectiveness in various aspects for students through enriching curricula and have reached the effectiveness of its role in developing the environmental and scientific culture with the aim of expanding students' perceptions and skills. This program has a positive impact on students 'acquisition of mathematical problem-solving skills that will help them in the future, and the design of this program works to challenge the students' abilities in order to develop their thinking in light of the quality standards of the outputs of unit collection of numbers within 9999 and its introduction to third-grade basic students' mathematics in Jordan.

The results of this study were in agreement with the results of the Abu Nahla study (2018), the Hajbi study (2017), the Al-Khatib study (2015), the Tunaboyin and Demir study (2017), and the Shman East study (Shman-East, 2015).

\section{Recommendations}

1. The necessity of developing an integrated and comprehensive plan by the Ministry of Education to use educational technologies in the educational process so that the plan includes providing the material, human capabilities and the appropriate infrastructure.

2. Activating the use of enrichment activities programs based on educational techniques in teaching mathematics for various educational stages, in order to raise the level of students' achievement, according to the results of the study.

3. Activating the use of enrichment activities in teaching the skill of addition and subtraction, as it is one of the basic skills, as if students fail to perform these skills, it will cause difficulties later in learning more complex skills.

\section{References}

Abdul Ghani, M. (2018). The effect of computer enrichment activities on learning some basic motor skills for first stage pupils in basic education. Unpublished MA thesis, Minia University: Arab Republic of Egypt.

Abu Nahla, D. A. A. (2018). The effect of using the interactive board on creative thinking in mathematics among eighth grade female students in Jordan. Master Thesis. Middle East University: Jordan.

Adam, B. M. (2012). Educational techniques in learning and teaching foreign languages. University of Khartoum: Sudan.

Al-Balawi, S. (2014). The degree of the contribution of learning technologies to students' participation with learning difficulties in the educational process in the schools of AlUla Governorate. Unpublished Master Thesis. Curriculum Department, College of Education, Yarmouk University: Irbid.

Al-Hailah, M. M. (2001) Basics of designing and producing educational aids, 2nd Edition, Amman: Dar Al-Masirah for Printing and Publishing

Al-Khatib, B. (2015). The effectiveness of using the electronic whiteboard in the achievement of sixth graders and their attitudes towards it. Master Thesis. The Hashemite University: Jordan. 
Ar-Rasheed, M. (2017). The impact of a proposed electronic learning environment on developing the academic achievement of female students in the first intermediate grade in the Mathematics course, the Fifth Conference on Teaching and Learning Mathematics, Teaching Mathematics, the Kingdom's Education Vision, 2030, the Saudi Society for Mathematical Sciences (Jisr), and the Ministry of Education.

As-Suruur, A. (2014). How to employ modern technique in teaching and learning mathematics, Journal of Educational Development, No. 54, 50-52, Sultanate of Oman.

Habibi, I. A. R. (2017). The effect of teaching a computerized unit mathematically using a tablet computer on the achievement of tenth graders in mathematics and improving their motivation towards learning it. Ph.D. The World Islamic Sciences University: Jordan.

Hadi, M. (2005). E-Learning via the Internet, Cairo: The Egyptian Lebanese House.

National Council of Teachers of Mathematics (NC TM). (2000). Principles and Standers for School Mathematics Reston, VA: NCTM.

Shman-East, S. (2015). The effect of computerized cognitive training on the working memory and mathematics achievement of low achievers. Unpuplished PHD thesis, Nova south eastern University.

Tasan, Abdel Rahman, N. (2015). The degree of application of accreditation standards and quality assurance in the administration of female students' affairs and student services at Imam Muhammad bin Saud Islamic University, Modern Education Association Journal - Egypt, 7 (23): 167-227.

Tunaboyiu, C., and Demir, E. (2017). The Effect of Teaching Supported by Interactive Whiteboard on Students' Mathematical Achievement in Lower Secondery Education, Journal of Educatiuon and Learning, 6(1),81-94.

Yahn, H. (2017). Instructional Technologies and Materials development. nobel publishing. Ankara. 